Ent r epr eneur Engi neering - a new concept of engi neering educati on

\begin{tabular}{|l|l|}
\hline 著者 & Tomi sawa Osamu, Kano Got a \\
\hline vol une & 1 \\
\hline page range & 344348 \\
\hline year & $2005-09$ \\
\hline URL & ht t p: //hdl . handl e. net /10173/332 \\
\hline
\end{tabular}




\title{
Entrepreneur Engineering - a new concept of engineering education
}

\author{
Osamu Tomisawa and Gota Kano \\ Kochi University of Technology \\ Tosayamada, Kochi, Japan
}

\begin{abstract}
Management education for engineering people who work in actual companies has become important these days. Specifically, adult education to foster people who can identify new business opportunity and who can create value by challenging new endeavors is crucial. In order to meet this requirement, entrepreneur engineering course was established at Graduate School, Kochi University of Technology in 1999. This paper describes a new concept of "Entrepreneur engineering". It also describes the adult education system which has been implemented utilizing real-time multi-location, bidirectional TV conference system.
\end{abstract}

Keywords- Entrepreneur Engineering, Management of Technology, MOT, Engineering Management, Intrapreneur

\section{Introduction}

Objective of this work is to provide a educational solution to the key issue of integrating technology and business strategy. Target students are engineering people who work in actual companies but non-engineering people can be included as well. Entrepreneur, typically, sounds like people who create a new venture company, but our understanding is that entrepreneur can be extended to people who pursue innovative activity in existing enterprises. These people are referred to as "intrapreneur" according to Pinchot [1]. So the source of potential target customer (students) area are big enterprise, small to medium companies, SOHO (small office home office), and non profit organization including local government. Our expected output of the education is not only to produce people who can create a venture, but also to produce engineers who understand management, and to produce people who work for his or her company with full of entrepreneurship.

Recently, MOT(Management Of Technology) education has been of great interest around the world. Early discussion in the management of technology was focused on managing technology as one of the management resources. It also was focused on technology strategy.

Tarek Khalil defined MOT as interdisciplinary fields that integrates science, engineering and management knowledge and practice. Traditional fields in science and engineering contribute to scientific discovery and to technology creation. Other traditional fields in business administration contribute to the management of enterprises, economics, finance, marketing, and public policy. Management of technology connects disciplines that focus on technology creation with those that enable its conversion to wealth [2]. Issues related to alignment of business and technology strategy was discussed by Yogendra comparing established and start-up business [3]. It suggests that new technology visioning and innovation will become an essential, mainstream discipline. It also insists necessity of a proactive approach to monitoring future and emerging technologies.

R.Ray Gehani has proposed the V-6 engine model of MOT in his book "Management of Technology and operations" [4]. He showed a metaphor of a turbo-charged V-6 engine for a yacht sailing in the ocean. The goal is to fight the pirates (competitors) and the stormy weather (economy) to get to an treasure island of profits. He divided MOT into three subsystems first of which is core-transformation subsystem composed of production operation, intellectual property and product development. The second subsystem which supports the first subsystem is composed of quality, information processing and people. Management of these 6 items corresponds to 6 cylinder of the turbo engine. The last subsystem is project management and leadership. The point of Gehani, to our understanding, is that above six items have to be synchronized just like cylinders in a engine, otherwise the output efficiency will be reduced significantly.

Kameoka proposed a concept of "techno-producer" who promotes radical innovation process to generate a new business and industry [5]. Role of the techno-producer is defined to be a person who sets up a strategic objective goal to create new innovation. The techno-producer generates new concept and strategies, and also it leads innovation process.

Okutsu et al has analyzed more than hundred of Japanese MOT education programs which were developed during 2002-2004, and categorized into four types [6]. This category includes "Technology Oriented Program", "Technology focused Program", "General management program" and "Special program". Major points observed in the study were; 1) entrepreneurship is a central topic, 2) innovation is main interest in technology focused program, 3) R\&D management is a major topic in technology oriented program.

One of the best definition of entrepreneurship was given by Kao [7]. It says that "Entrepreneurship is the attempt to create value through recognition of business opportunity, the management of risk-taking appropriate to the opportunity, and through the communicative and management skills to mobilize human, financial, and material resources necessary to bring a project to fruition."

Entrepreneur Engineering Course was established at 
Graduate School, Kochi University of Technology in 1999. The new term, Entrepreneur Engineering, was conceptually defined as a dynamic process for business creation starting from technical seeds with entrepreneurial mind [8]. The purpose of this paper is to describe the new concept of "Entrepreneur Engineering" in more systematic and logical way, and to describe actual implementation of the education program. The approach is to re-define the entrepreneur education course from engineering point of view. In other words, a business creation process from technology seeds should be viewed as engineering in order to give clear and systematic vision to the process[9]. This was a part of reason that the entrepreneur course has been established in the engineering college.

\section{Entrepreneur Engineering}

Engineering can be viewed as a system composed of "input", "transformation process" and "output" as shown in Fig.1. The input is "knowledge" or "technology", and output is "products" or "more sophisticated technology".

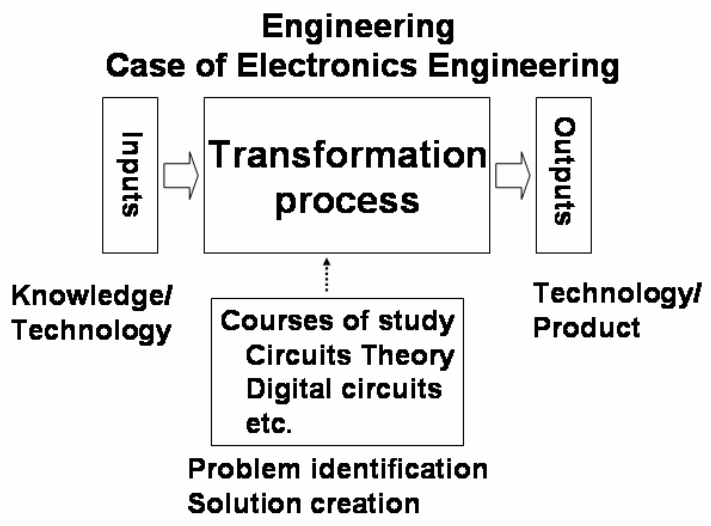

Fig.1 Engineering as a system

The transformation process provides methodology to identify a problem and give a solution to the problem. Let' take electronics engineering as an example. This

\section{Entrepreneur Engineering}

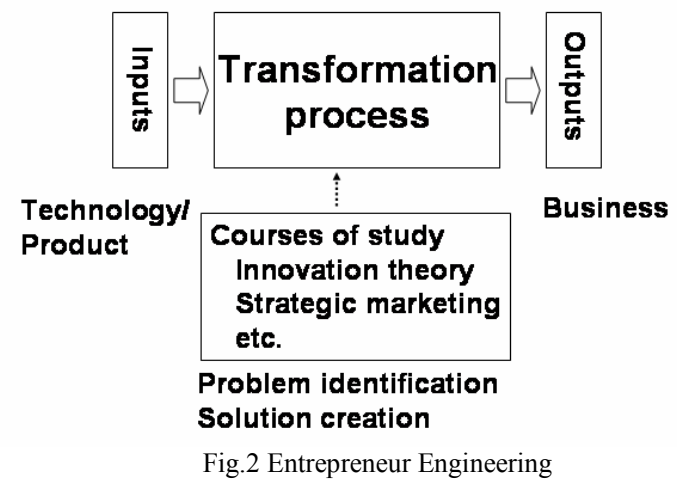

Education for the transformation process is implemented by a courses of study including "Circuits theory", "Computer organization", "Digital circuits", "Integrated circuits", "Signal Processing", and so on. These courses give an idea to convert specific technology to a product. Similarly, "Entrepreneur engineering" can be defined as a system with "input", "transformation process" and "output" as shown in Fig.2. The input is "technology" or "products" and output is "business". A function of the transformation process is to give methodology for creating business from the inputs. In the same way as Electronics Engineering, the courses of study in the entrepreneur engineering are composed of "Theory of entrepreneur", "Entrepreneur marketing", "Innovation theory", "Management theory", "Intelligent property right", and so on. This set of courses gives people methodology for business creation. A computer scientist, Niklaus Wirth, mentioned that "Algorithm + Data Structure = Program". A program is an software implementation of specific function and two major factors in program development are "Data Structure" and "Algorithm". When you try to solve a problem, you will have to define or select appropriate "data structure". Data structure is abstraction of vast amount of information and data in the real world. The abstraction is simplification of facts. You need to select a method to abstract the real world. It is to define a data set which can express real situation. Once the data structure is selected, the target function can be

\section{Analogy to Computer Science \\ Data Structure + Algorithm $=$ Program}

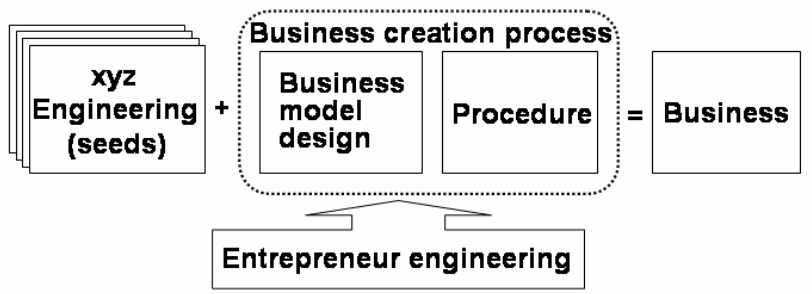

Fig. 3 Analogy to Computer Science

implemented by operation defined by appropriate algorithm which is a set of steps to achieve a desired result. It shows operation to the data structure. This analogy can be applied to the business creation process. As mentioned earlier, integral part of the transformation process from technology/product to business is identification of problem and to create solution for the problem. Business creation process can be divided into two portions, first of which corresponds to "data structure". It is abstraction of real world and clarification of problem for business creation. Since business is things to be designed, this portion can be viewed as a business model design in a broader sense. This may be a new design, selection from existing models or combination of models. Entrepreneur marketing, innovation theory and so on will help to improve this design capability. Second portion corresponds to "algorithm" and it provides procedure for business creation. This is covered by a subject like entrepreneur theory. Business model design and procedure is associated with each other. This combination of 
business model design and procedure makes another "algorithm" in upper level of hierarchy. Since source of seeds

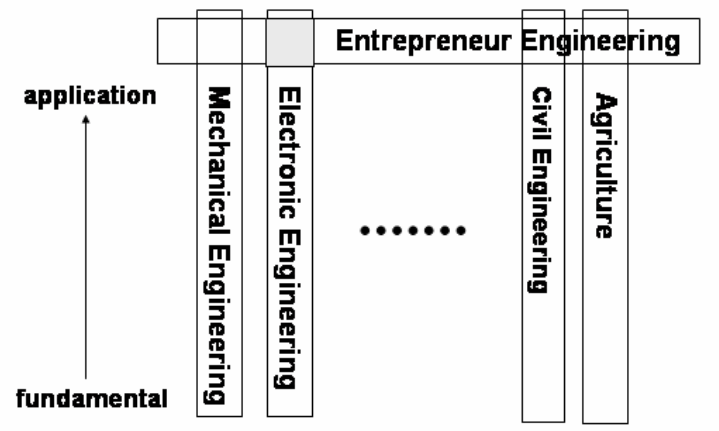

Fig. 4 Functional position of Entrepreneur engineering

comes from variety of engineering, here we can say that "xyz-engineering + entrepreneur engineering makes business". Relation of entrepreneur engineering to other engineerings is just like weft and warp thread relation in a textile. Electronics engineering, chemical engineering, machine engineering are warps running in vertical direction, while entrepreneur engineering runs horizontally crossing warps as a weft thread.

Entrepreneur engineering is not an engineering course arranged in parallel to other engineering courses in the faculty of engineering, rather it is a course common to other engineering. Overlapping area of an engineering course and entrepreneur engineering course in Fig. 4 can be treated as a seed of business creation process for commercialization.

Positioning of entrepreneur engineering is shown in Fig. 5 as a three dimensional view. Here are three horizontal plains shown. The top is business plain and next to the top shows product plain. The bottom is knowledge plain or technology plain, two axes of which are technology and area

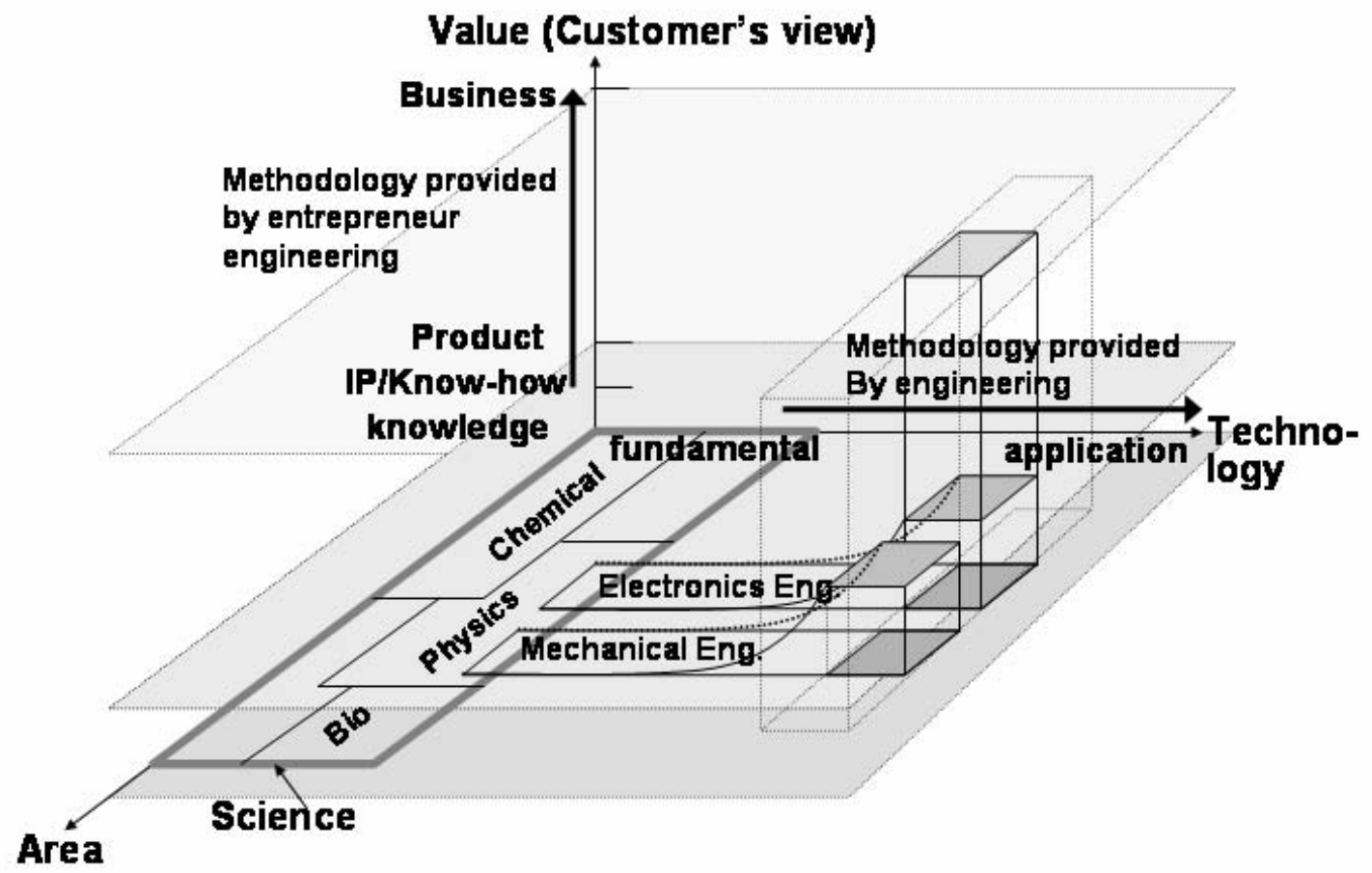

Fig. 5 Model of Entrepreneur engineering

of the technology. Technology axis goes from fundamental to more application oriented to the right. Leftmost side in the technology plain shows science area composing of variety of science area like physics, chemical and so on. Engineering region expands from science area to the right. Now we can add another dimension, that is to say "value from the point of customers". Bottom of the vertical axis is knowledge level and it goes to IP level, product level and eventually to the business level. Engineering starts from science area and moves to the right. It is covered from fundamentals to product level by engineering, in other words, engineering education provides methodology to transform scientific knowledge up to product level. Entrepreneur engineering can be expressed by a box standing at application area at engineering. It moves in the vertical direction in Fig.5 and it shares a cube, which is sandwiched by product plan and knowledge plane, with engineering. Movement to vertical direction is cultivated by entrepreneur engineering education.

Process to create business from technology seeds can be expressed by four steps as shown in Fig. 6.

The starter is identification of market needs which may be latent but sometimes it is clear. The second step is value creation followed by business development. The last step is management. Entrepreneur engineering covers all these four steps. Entrepreneur engineering is a bundle of courses of study which provides methodology to go through these steps. For examples, "Entrepreneur marketing" covers steps from market needs to value creation. Innovation theory covers 
market needs to business development, and Theory of entrepreneur covers value creation through business development. Topics covered by entrepreneur engineering is rather dynamic process as opposed to one covered by typical management.

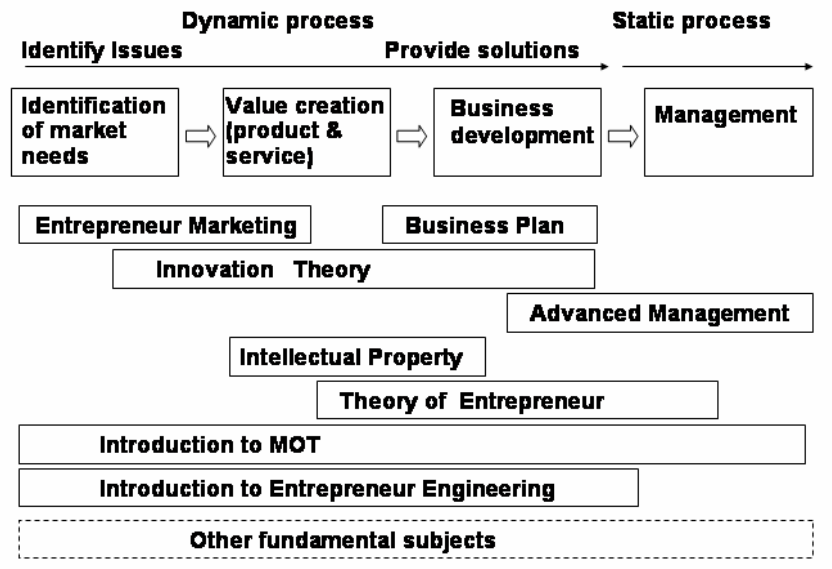

Fig. 6 Entrepreneur engineering curriculum structure

\section{Implementation of education program}

The Entrepreneur Engineering Course was established in 1999 at Kochi University of Technology as a graduated school. This was the first implementation of this kind of course in an engineering college in Japan.

\section{A. Curriculum}

The curriculum has a three layer structure considering future flexible expansion. The bottom is fundamentals like
"Financing and Accounting", "Introduction to Economics" the middle layer is the core subjects composing of "Innovation theory", "Theory of Entrepreneur Engineering", "Advanced Management" "Entrepreneur Marketing" "Business Plan", and so on. The top layer is relatively application oriented and it includes "International Business Collaboration", "Business Management in Practice" etc. Typically, lecture is a combination of general theory and actual cases. This was a pioneer graduated school program in Japan. Primary objective of this course was to provide management and entrepreneurship education for industry engineers. Since almost all the students have jobs, the class is open during weekends. The course is so called a condensed course and one course of study consists of 4 days lecture each of which is 6 hours long. So, in order to complete one course, it is required to attend the class on Saturday and Sunday in the first week, and on Saturday and Sunday in the third week, skipping one week in between.

\section{B. Interactive TV conference system}

Potential students reside all over Japan because of nation-wide requirement for this kind of engineering education. Initially, three classrooms were prepared. Main classroom is located in Kochi and two satellite classrooms are located in Tokyo and Osaka. These class rooms are connected through high speed optical communication networks implementing real-time, multi-location, bidirectional TV conference system for the course operation. The bandwidth of the network is $384 \mathrm{Kbps}$ and it shows pretty high level of image and sound quality for the interactive lecture/discussion.

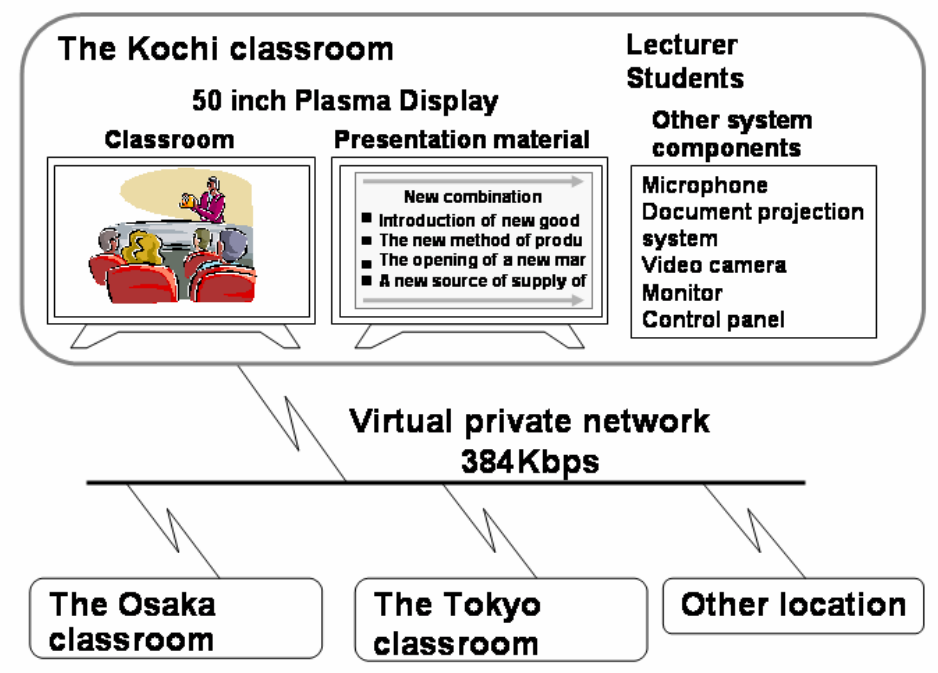

Fig. 7 Real time, bidirectional TV conference system

The system composed of microphones, document projection system, video camera, monitor and console for overall control. Communication capability among a lecturer and students is very important issue if we use a remote lecture system. It has been realized by adopting two big, high-resolution plasma display systems to each class room.

Students in any classroom can interrupt a lecture by simply turning on their microphone switch to initiate 
discussion. One display in a satellite class room shows lecturer's visual aids from Kochi main classroom and another display shows most recently activated classroom.

Three real physical classrooms are combined by the system through networks resulting in a single virtual classroom which provides a filed of discussion for the students and lecturer.

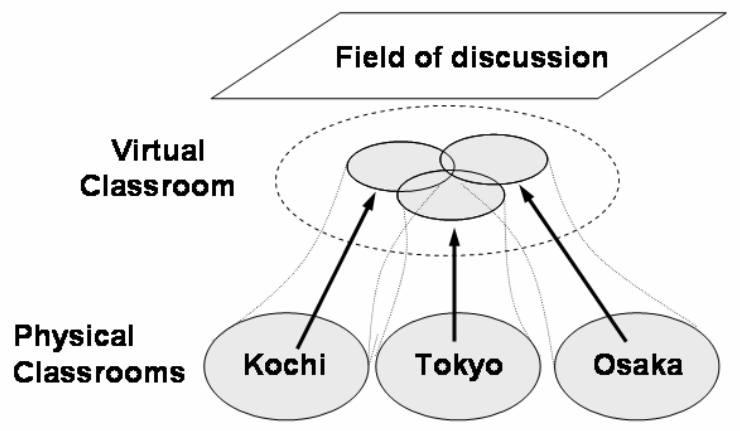

Fig.8 Implementation of a virtual class room

This system was also applied to international seminar connecting to universities in USA and China in addition to three classrooms in Japan. It worked well even for panel discussion.

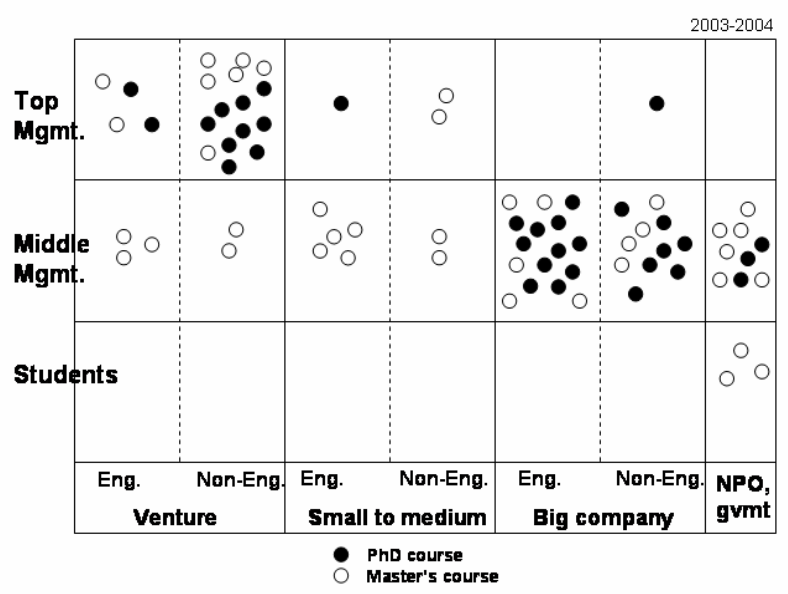

Fig. 9 Background of students

Background of students are shown in Fig.9. Students come from variety of organization. Major source turned to be middle managements in the big enterprises and top management in venture companies. Number of engineering people and non-engineering people is approximately same.

As part of performance of the entrepreneur course, students and graduates created 10 venture companies so far. Other graduates have been working in their companies as an active intrapreneur.
IV. Conclusion

A new concept of engineering education, entrepreneur engineering was defined as a transforming system having input and output. The entrepreneur engineering is a bundle of courses of study which support business creation process. This provides a methodology to transfer technology seeds to business. Actual education system for adult has been implemented utilizing real-time multi-location, bidirectional TV conference system. Three classrooms, Kochi, Tokyo and Osaka have resulted in a single virtual classroom.

\section{Acknowledgment}

The authors would like to thank Dr. Yasuharu Suematsu for his initiative and concept creation of entrepreneur engineering course at Kochi University of Technology..

Many people have been involved in implementation of the course, but special thanks go to Dr. Hiroyuki Mizuno for his tremendous effort for the course establishment. The authors would like to thank Dr. Hajime Okamura for his continuous support throughout the works.

\section{References}

[1] Gifford Pinchot III, "Intrapreneuring", Harper \& Row Publishers, 1985.

[2] T. Khalil "Management of Technology, the key to competitiveness and wealth creation", McGraw-Hill, pp.7-11, 2000.

[3] S. Yogendra and S. Sengupta, "Aligning Business and Techonology Strategies - A Comparison of established and start-up business contexts", IEEE International Engineering Management Conf. pp. 2-7, 2002.

[4] R. Ray Gehani "Management of technology and operations", John Wiley \& Sons, 1998.

[5] A. Kameoka, "New Direction and Strategy of MOT Practice in Japan -from "Just-in-Time Production" to "Just-in-Time Innovation", IEEE International Engineering Management Conf. pp. 342-347, 2004.

[6] S. Okutsu, Y. Ikawa and A. Kameoka, "Analysis of Japanese MOT Education Requirements by a Needs-Seeds Matrix", IEEE International Engineering Management Conf. pp. 248-252, 2004.

[7] J. J. Kao, "The entrepreneur"Printice-Hall, 1991

[8] G. Kano, "Education and research in entrepreneur engineering graduated course", Research Bulletin, Kochi University of Technology: Vol.1, No.1,P.22, 2004 (in Japanese).

[9] O. Tomisawa "Technical marketing and engineering education", Kansai Engineering Education Association $78^{\text {th }}$ annual meeting, Feb. 2005. (in Japanese) 